\title{
Prácticas de earning management en el sector retail de Chile. El caso La Polar*
}

\section{Earning Management Practices in the Chilean Retail Sector. The La Polar Case \\ Práticas de earning management no setor retail do Chile. O caso La Polar}

Edinson Cornejo-Saavedra ${ }^{a}$

DOI: https://doi.org/10.11144/Javeriana.cc18-45.pems

Universidad del Bio-Bio, Chile

ecornejo@ubiobio.cl

ORCID: http://orcid.org/0000-0002-6153-9478

Fecha de recepción: 02 Agosto 2016

Paz Arias-Muñoz

Fecha de aprobación: 16 Octubre 2016

Universidad del Bio-Bio, Chile

ORCID: http://orcid.org/0000-0001-6292-950X

Luis Améstica-Rivas

Universidad del Bío-Bio, Chile

ORCID: http://orcid.org/0000-0003-0482-0287

Nataly Guinez-Cabrera

Universidad del Bío-Bio, Chile

ORCID: http://orcid.org/0000-0002-6109-8457

\section{Resumen:}

Las prácticas de earnings management ocurren cuando una firma usa la discrecionalidad en la elaboración de sus estados financieros y en la estructuración de sus transacciones, para alterar los beneficios reportados e inducir a error a los agentes interesados en el desempeño de la compañía; el fraude contable es la forma extrema de este tipo de prácticas. Este estudio analizó los efectos de una práctica extrema de earnings management - la repactación unilateral de créditos morosos- en los estados financieros e indicadores de desempeño de La Polar; y evaluó el efecto de la revelación de tales prácticas en los retornos accionarios de la firma y del sector retail de Chile. Se concluyó que la contabilidad de repactaciones mejoró la apariencia de los estados financieros y los indicadores de la firma; y que, una vez revelada esta situación, el mercado castigó el precio de las acciones de La Polar y también de las otras compañías de retail, ante las sospechas de que estas también realizaran repactaciones no reveladas en sus estados financieros.

Códigos JEL: M41, G14, G39

Palabras clave: Earnings management, provisiones por incobrables, repactaciones unilaterales, fraude, retail.

\section{Abstract:}

Earnings management practices occur when a firm uses discretion in the preparation of its financial statements and in the structuring of its transactions as to alter the reported benefits and mislead the stakeholders interested in the performance of the company. Accounting fraud is the extreme form of this type of practice. This study analyzed the effects of an extreme practice of earnings management -the unilateral renegotiation of non-performing loans- in the financial statements and performance indicators of La Polar; and evaluated the effect of the disclosure of such practices on the stock returns of the firm and the Chilean retail sector. It was concluded that renegotiation accounting improved the appearance of the financial statements and indicators of the firm and that, once this situation was revealed, the market punished the price of the shares of La Polar and also of the other retail companies, given the suspicion that these also carried out unrevealed renegotiations in their financial statements.

Keywords: Earnings management, provisions for uncollectible debts, unilateral renegotiations, fraud, retail.

\section{Resumo:}

As práticas de earnings management sucedem quando uma firma usa a discrição na preparação das suas demonstrações financeiras e na estruturação das transações, para alterar os benefícios relatados e induzir a erro os agentes interessados no desempenho da companhia; a fraude contábil é a forma extrema desse tipo de práticas. Este estudo analisou os efeitos de uma prática extrema Notas de autor 
de earnings management — a repactuação unilateral de créditos inadimplentes — nas demonstrações financeiras e indicadores de desempenho de La Polar e avaliou o efeito da divulgação de tais práticas nos retornos acionários da firma e do setor retail no Chile. Concluiu-se que a contabilidade de repactuações melhorou a aparência das demonstrações financeiras e os indicadores da firma; e que, uma vez revelada esta situação, o mercado puniu o preço das ações de La Polar e também das outras companhias de retail, ante a suspeita de elas também realizarem repactuações não reveladas nas suas demonstrações financeiras.

Palavras-chave: Earnings management, provisões por incobráveis, repactuações unilaterais, fraude, retail.

\section{Introducción}

El jueves 9 de junio de 2011, el precio de la acción de La Polar S.A., una de las principales firmas de retail de Chile, se desplomó. El 8 de junio el precio de cierre fue CLP 2.336,2 y el 09 de junio el precio disminuyó a CLP $1.352,2$, y perdió un $42,1 \%$ del valor de mercado de su patrimonio en solo un día de transacción. La caída del precio ocurrió inmediatamente después de que La Polar informó un "hecho esencial" a la Superintendencia de Valores y Seguros (SVS) de Chile (2011), que fiscaliza las entidades de los mercados de valores y de seguros, y otras entidades establecidas por ley; y esta institución lo hizo público.

En el "hecho esencial", La Polar informó sobre sus políticas y prácticas de renegociación de las deudas morosas de sus clientes tenedores de la tarjeta de crédito emitida por la firma. La Polar informó a la SVS (2011) acerca de prácticas (conocidas como repactaciones unilaterales de créditos morosos) que se habrían efectuado sin autorización del Directorio y en disconformidad con los criterios y parámetros establecidos por la compañía. Corregir estas prácticas podía elevar entre CLP 150.000 millones (US $\$ 321$ millones) y CLP 200.000 millones (US\$428 millones) las provisiones por créditos con riesgo de incobrabilidad, casi 10 veces las provisiones realizadas en 2010 (que sumaron CLP 22.000 millones). Al día siguiente, en su edición del viernes 10 de junio, el periódico La Tercera, de gran circulación en el país, tituló: La Polar pierde el 42\% de su valor en un día por escándalo financiero ${ }^{1}$.

La repactación y la renegociación eran "operaciones en que se cambian irreversiblemente las condiciones originales pactadas en el crédito, tales como valor cuota, plazo y monto de la deuda” (Traslaviña, 2013, p. 102). Según Hugo Traslaviña (2013), la renegociación unilateral era una operación en que el cliente supuestamente quedaba al día en el pago de su deuda. Para ello, el monto adeudado por el cliente era dividido en seis nuevas cuotas, con el primer vencimiento en un plazo de hasta 60 días. Por lo general, la operación consistía en otorgar, contablemente, un nuevo crédito al cliente moroso. Con este nuevo crédito, se pagaba el total de la deuda original, incluyendo intereses y gastos de cobranza. Esta operación generaba una nueva deuda, con un nuevo plazo de pago. La nueva deuda quedaba reflejada en una única boleta que era enviada por correo a los clientes-deudores, que en ese momento se daban cuenta de que la empresa había renegociado y repactado sus deudas, de manera unilateral, sin que ellos la hubiesen autorizado, y que el monto de la deuda original se había duplicado o triplicado.

Este trabajo estudia el efecto de una práctica extrema de earnings management en el sector retail de Chile. Se investiga cuáles fueron las prácticas contables realizadas por La Polar S.A., relativas a deudores morosos, y sus efectos en los estados financieros e indicadores de desempeño de la firma, y cómo la revelación de tales prácticas afectó los retornos accionarios de esta compañía y del sector retail de Chile.

\section{Earnings management}

El concepto de earnings management ha sido definido por Brad A. Badertscher, John D. Phillips, Morton Pincus y Sonja Olhoft Rego (2009); David Burgstahler y Michael Eames (2006), Sidney Davidson, Clyde P. Stickney y Roman L. Weil (1987), Patricia M. Dechow y Douglas J. Skinner (2000), Paul M. Healy y James M. Wahlen (1999), Hsiang-Lin Chih, Chung-Hua Shen y Feng-Ching Kang (2008); Katherine 
Schipper (1989), y Martin Walker (2013), entre otros. Se destacan Paul M. Healy y James M. Wahlen (1999), para quienes la práctica de "earnings management ocurre cuando la gerencia usa la discrecionalidad en la elaboración de los estados financieros y en la estructuración de las transacciones para alterar los reportes financieros, ya sea para inducir a error a alguna de las partes interesadas en el desempeño económico de la firma (stakeholders) o para influir en los resultados contractuales que dependen de las cifras contables reportadas". También se destaca el artículo de Beatriz García-Osma, Belén Gill de Albornoz y Ana GisbertClemente (2005), que centran la definición en la manipulación de la cifra de resultado contable, considerada por los agentes del mercado como el resumen del desempeño financiero de la compañía. Sin embargo, para Patricia M. Dechow y Douglas J. Skinner (2000), hay una forma extrema de earnings management, el fraude contable, definido como "la omisión o declaración errónea, deliberada, intencional, de hechos materiales o datos contables, la cual es engañosa y, cuando es considerada con toda la información disponible, podría causar que el lector cambie o altere su juicio o decisión" (National Association of Certified Fraud Examiners 1993, p. 12).

\section{La teoría del fraude}

Donald R. Cressey investigó sobre el comportamiento delictual. A partir de entrevistas con prisioneros en la Illinois State Penitentiary en Joliet, Illinois, Cressey notó características comunes entre los convictos que cumplían condenas por delitos de "cuello blanco". Con base en sus observaciones, Cressey (1950, 1953) propuso tres criterios para las transgresiones ilegales de la confianza: (1) tener un problema financiero no compartible; (2) conocer el funcionamiento de una empresa y tener la oportunidad para transgredir una posición de confianza; y (3) poseer la habilidad para ajustar la autopercepción, de manera que transgredir esa confianza no constituya, en la mente del individuo, un comportamiento criminal. Cressey $(1950,1953)$ planteó la hipótesis de que, para que el fraude ocurra, cada uno de esos tres criterios debía estar presente: (1) presión financiera percibida, (2) oportunidad percibida, y (3) racionalización. Una representación de su teoría evolucionó en lo que hoy se conoce como el "Triángulo del Fraude”, ilustrado en la figura 1 (Dorminey, Fleming, Kranacher \& Riley, 2012).

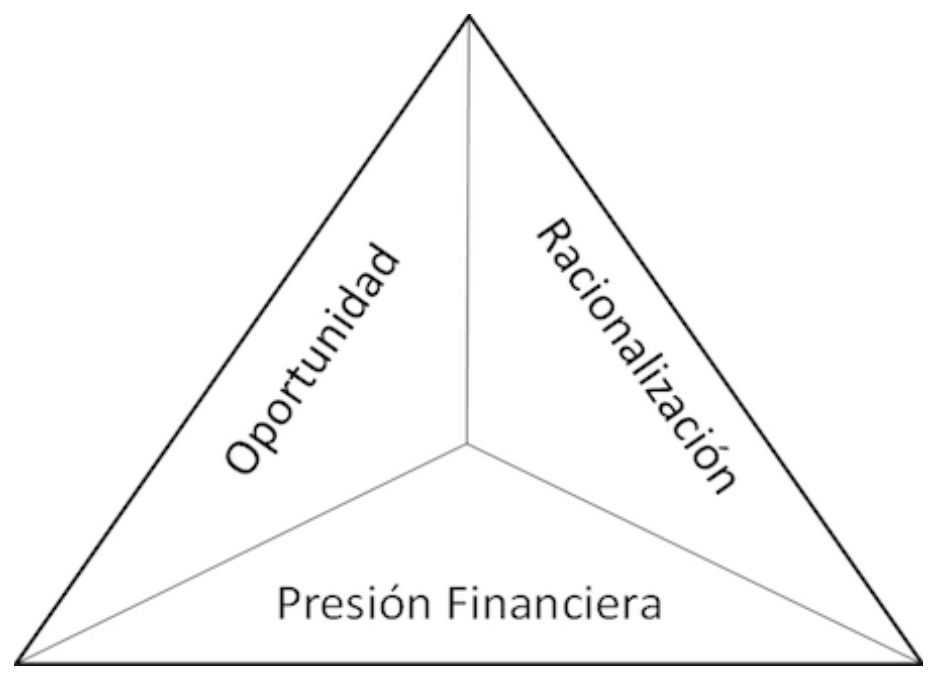

FIGURA 1

El triángulo del fraude

Fuente: Dorminey et al. (2012)

De acuerdo con el análisis de Jack Dorminey et al. (2012), primero, la presión percibida de un problema financiero no compartible crea el motivo para el delito. Un individuo puede considerar un problema 
como no compartible, debido a que percibe el estigma social relacionado con tener ese tipo de problema. Adicionalmente, un ego fuerte y el orgullo pueden impedir que un individuo busque ayuda o cuente el problema. Segundo, la oportunidad percibida es la percepción de un punto débil en los sistemas de control de una organización y de que la probabilidad de ser atrapado es remota. Por lo tanto, la oportunidad percibida requiere la habilidad para cometer el acto y de hacerlo sin ser detectado. Tercero, la racionalización es un intento para reducir la disonancia cognitiva dentro del individuo (Festinger, 1957; Ramamoorti, 2008; Ramamoorti, Morrison \& Koletar, 2009). Cressey $(1950,1953)$ observó que los individuos que cometen fraude desean permanecer dentro de su zona de confort moral. Por lo tanto, al menos internamente, el defraudador busca justificar la acción fraudulenta antes del primer acto de fraude. Cressey $(1950,1953)$ notó que el perpetrador del fraude no desea ser considerado como un transgresor de la confianza, sino que prefiere estimar su dilema como una excepción, una situación que le permite no verse a sí mismo de una forma negativa. Mediante la racionalización, el perpetrador es capaz de reducir la disonancia y proceder sin remordimientos. El triángulo del fraude fue desarrollado sobre estas tres observaciones fundamentales, y forma la base para la mayor parte de las discusiones de los delitos de "cuello blanco".

Dorminey et al. (2012) revisaron el Triángulo del Fraude, resaltando los recientes hallazgos y el pensamiento contemporáneo en la comunidad antifraude, para desarrollar un metamodelo del fraude que podría ser utilizado en la instrucción e investigación contable. Gregory M. Trompeter, Tina D. Carpenter, Naman Desai, Keith L. Jones y Richard A. Riley (2013) realizaron una síntesis de la literatura académica relacionada con los reportes financieros fraudulentos, y extendieron el trabajo de Chris E. Hogan, Zabihollah Rezaee, Richard A. Riley y Uma K. Velury (2008). Trompeter et al. (2013) sintetizaron la investigación en un modelo que ilustra la aproximación al fraude desde la perspectiva del auditor. El modelo incorpora: el uso del Triángulo del Fraude por parte del auditor (los incentivos de la gerencia, la oportunidad para cometer el fraude y la actitud); la evaluación de la existencia y efectividad de medidas antifraude (por ejemplo, mecanismos de gobernanza corporativa y controles internos); y la consideración de posibles estrategias de fraude y técnicas de ocultamiento, cuando se hace una evaluación global del riesgo de fraude de un cliente. Además, el modelo ilustra cómo los auditores pueden incorporar su evaluación en una estrategia global para detectar fraudes, mediante la implementación adecuada de procedimientos de detección de fraudes. Gran parte del trabajo previo ha estado concentrado en el Triángulo del Fraude: presión (incentivo), oportunidad y racionalización (actitud). Sin embargo, Trompeter et al. (2013) presentaron un modelo que concentra y extiende las ideas acerca del rol del auditor con respecto a la evaluación del riesgo de información financiera fraudulenta, al mismo tiempo que lo impide y lo detecta. El modelo sugiere que los procedimientos de detección de fraude deben ser diseñados en el programa de auditoría con base en el Triángulo del Fraude, tanto como en los elementos del fraude (el acto en sí, el ocultamiento del fraude o conversión de ganancias fraudulentas).

Por otra parte, Saif Ullah, Nadia Massoud y Barry Scholnick (2014) estudiaron el efecto de la información fraudulenta sobre el valor patrimonial. De acuerdo con estos autores, hay dos tipos de manipulaciones del precio accionario examinados en la literatura: (1) insider trading, que involucra información privada verdadera; y (2) la difusión pública de información fraudulenta. Ullah et al. (2014) señalaron que su artículo era la primera investigación empírica que examinaba el impacto de la información pública fraudulenta, falsa, sobre los precios accionarios y el volumen de transacción. Los autores encontraron que la información era falsa, aun después de ser denegada por una fuente creíble tal como la US Securities and Exchange Commission, SEC, generó retornos y volúmenes de transacción anormales (la US Securities and Exchange Commission, SEC, es la institución estadounidense cuya misión es proteger a los inversionistas; mantener mercados justos, ordenados y eficientes; y facilitar la formación de capital). Ullah et al. (2014) también encontraron que los efectos de la información falsa sobre los retornos y el volumen pueden ser persistentes por al menos dos semanas, y mostraron que los perpetradores de los ataques con noticias falsas pueden obtener grandes beneficios a partir de ese tipo de manipulaciones del mercado. 


\section{La teoría prospectiva acumulativa y el fraude financiero}

En otra línea de investigación se encuentra la teoría prospectiva acumulada (cumulative prospect theory o CPT) desarrollada por los psicólogos Amos Tversky y Daniel Kahneman (1992) ${ }^{2}$, que predice el siguiente patrón de actitudes de riesgo: los individuos son buscadores de riesgo (aversos al riesgo) en relación con ganancias de baja probabilidad (pérdidas) o pérdidas de alta probabilidad (ganancias); el individuo evalúa las ganancias y las pérdidas desde un punto de referencia.

Ya que un reporte financiero fraudulento es riesgoso para la riqueza de un gerente, Michael K. Fung (2015) investigó si la incidencia de reportes financieros fraudulentos seguía el patrón de actitud hacia el riesgo implícito en la CPT. Para Fung (2015), la información financiera fraudulenta es un acto criminal. Este autor señaló que, desde el artículo pionero de Gary S. Becker (1968), los economistas han utilizado la teoría de la utilidad esperada $\left(E^{2} T^{3}\right)$ para modelar la elección delictiva (Schmidt \& Witte, 1984). Según la EUT, un acto delictivo es solamente el resultado de un cálculo racional de costo-beneficio, lo que implica que, bajo las circunstancias adecuadas, cada individuo — no solo el "tipo delictivo" - escoge cometer un delito. Sin embargo, la evidencia sugiere que los delincuentes y no delincuentes tienen distintas actitudes frente al riesgo. Para Michael K. Fung (2015), los estudios de Michael K. Block y Vernon E. Gerety (1995), Jeffrey Grogger (1991) y Ann Dryden Witte (1980) demostraron que los delincuentes exhiben una mayor sensibilidad a la certeza del castigo que a su severidad, mientras que ocurre lo opuesto con los no delincuentes. Como Gary $S$. Becker (1968) demostró, este patrón de sensibilidad implica que los delincuentes son amantes del riesgo, lo que los hace diferentes de los no criminales en términos de la actitud ante el riesgo (Fung, 2015).

Por otra parte, Natasha Burns y Simi Kedia (2006) y Joseph P. O'Connor, Richard L. Priem, Joseph E. Coombs y K. Matthew Gilley (2006) descubrieron que la probabilidad de reportar información financiera fraudulenta estaba asociada con las compensaciones basadas en opciones, porque la convexidad de este tipo de compensaciones induce al gerente a tomar riesgos adicionales. Estos resultados sugieren que, para una determinada probabilidad de ser detectado, es más probable que en la elaboración de información financiera fraudulenta se vea involucrado un gerente amante del riesgo que un gerente averso al riesgo (Fung, 2015). De acuerdo con Fung (2015), falsear los resultados financieros con la intención de engañar o confundir a los inversores es una forma arriesgada de mejorar la apariencia financiera de corto plazo de la firma, ya que ambos - la empresa y el gerente culpable - enfrentarán severas penas si aquello es finalmente detectado y revelado (por ejemplo, Hennes, Leone \& Miller, 2008; Karpoff, Lee \& Martin, 2008). Sin embargo, a menudo un gerente tiene mucho por perder financieramente si la firma muestra un bajo desempeño en relación con lo esperado, y tiene mucho por ganar si la empresa muestra un desempeño superior (Fung, 2015).

\section{Fraudes contables}

En relación con el ambiente propicio para un fraude contable, Claire E. Crutchley, Marlin R. H. Jensen y Beverly B. Marshall (2007) examinaron las características de gobierno, la calidad de las ganancias, las tasas de crecimiento, la política de dividendos y la estructura de compensaciones de 97 firmas investigadas por la SEC por fraudes contables. Los resultados mostraron que el ambiente corporativo más propenso a provocar un escándalo contable se manifestó en un crecimiento significativo y en prácticas contables que estaban un paso más allá del suavizamiento de los beneficios. Los autores concluyeron que las empresas que operan en este ambiente parecen más propensas a inclinarse al fraude, si hay menos personas independientes en el comité de auditoría y los directores externos están sobrecargados de trabajo.

Con respecto a las razones para llevar a cabo un fraude contable, según Gerard M. Zack (2009), hay varias razones para cometer un fraude en la elaboración de los reportes financieros de una organización. Algunas de ellas son los beneficios financieros directos para los perpetradores, como bonificaciones por el cumplimiento 
de metas; incrementos en el precio de las acciones de la compañía y en el valor de las stock options, como consecuencia de reportar fuertes resultados financieros; y mantener la plaza de trabajo por medio de la falsificación del éxito financiero de un departamento, línea de producto, etc., que pudo ser eliminado debido a su bajo desempeño.

Hay otras razones para perpetrar un fraude en la elaboración de los reportes financieros, pero son menos obvias y pueden no involucrar ganancias financieras directas, como presiones desde la administración superior, el consejo de directores y grupos externos (como analistas bursátiles) para lograr los beneficios esperados; presiones competitivas para superar a otras firmas de la industria; presiones para cumplir con los covenants financieros de los bonos corporativos emitidos por la empresa; el deseo de convencer a los prestamistas de que la firma es merecedora de un nuevo crédito o de un incremento en la línea de crédito; el deseo de persuadir a las aseguradoras de que la compañía tiene un bajo nivel de riesgo; y el deseo de convencer a los inversionistas de que el negocio es una valiosa alternativa de inversión (Zack, 2009).

En otro estudio, Rasa Kanapickienè y Živilè Grundienè (2015) señalaron que las dificultades financieras pueden motivar a los gerentes a participar en actividades fraudulentas. Y que una baja liquidez puede ser un incentivo para que los gerentes se involucren en la elaboración de estados financieros fraudulentos. Rasa Kanapickienè y Živilè Grundienè (2015) citaron a Xin-Ping Song, Zhi-Hua Hu, Jian-Guo Du y Zhao-Han Sheng (2014) y James D. Stice (1991), para quienes otra motivación de fraude es continuar creciendo.

En cuanto a las formas en que un fraude contable puede materializarse, de acuerdo con Zack (2009), los reportes financieros fraudulentos pueden ser consumados por medio de planes que consigan uno o más de los siguientes engaños: inflar activos; omitir o minimizar pasivos; inflar los ingresos por ventas; subestimar gastos; crear diferencias temporales, al adelantar el reconocimiento de ingresos o retrasar el reconocimiento de gastos; clasificar erróneamente ítems del balance general para mejorar algunos indicadores financieros; $y$ omitir notas explicativas que revelan aspectos claves de los estados financieros o declarar hechos falsos.

En relación con los métodos de detección de fraudes contables, Kanapickienè y Grundienè (2015) señalaron que, de acuerdo con las investigaciones de varios autores (Beneish, 1999; Fanning \& Cogger, 1998; Feroz, Kwon, Pastena \& Park, 2000; Lenard \& Alam, 2009; Persons, 1995; Ravisankar, Ravi, Raghava-Rao \& Bose, 2011; Spathis, Doumpos \& Zopounidis, 2002; Stice, 1991; Wells, 1997), el análisis de las ratios fue escogido como uno de los métodos para determinar fraudes. Las referencias literarias indican que el uso de ratios financieras para detectar informes financieros fraudulentos es un medio conveniente y directo. Sin embargo, surge el problema de interpretar el resultado, es decir, determinar cuál es el valor de la ratio financiera que indica que un informe es fraudulento (Kanapickienè \& Grundiené, 2015).

Por otra parte, Joseph F. Brazel, Keith L. Jones y Mark F. Zimbelman (2009) examinaron si los auditores pueden utilizar medidas no financieras para evaluar lo razonable del desempeño financiero y, de este modo, ayudar a detectar fraudes en los reportes financieros. Brazel et al. (2009) señalaron que si los auditores $\mathrm{u}$ otros interesados (directores, acreedores, inversionistas, reguladores, etc.) pueden identificar medidas no financieras (por ejemplo, el crecimiento de las instalaciones) que estén correlacionadas con medidas financieras (por ejemplo, el crecimiento de los ingresos), los patrones contradictorios entre las medidas no financieras y las medidas financieras podrían ser usados para detectar firmas con alto riesgo de fraude. Brazel et al. (2009) también encontraron que la diferencia entre el rendimiento financiero y el no financiero fue significativamente mayor para las empresas que cometieron fraude, y que estas diferencias estaban positivamente asociadas con información financiera fraudulenta. Los resultados sugieren que las medidas no financieras pueden ser utilizadas eficazmente para evaluar el riesgo de fraude.

En otro aspecto de los fraudes contables, la Association of Certified Fraud Examiners (ACFE), en su reporte de 2014, señaló que los fraudes profesionales pueden ser clasificados en tres categorías: apropiación indebida de activos, corrupción y fraude de estados financieros. La apropiación indebida de activos es el fraude más común (ocurrió en el $85 \%$ de los casos analizados) y el menos costoso (con una pérdida mediana de US $\$ 130.000)$. La corrupción se registró en el $37 \%$ de los casos, con una pérdida mediana de US\$200.000. Y solo 
el 9\% de los casos analizados involucró fraudes de estados financieros, no obstante, estos tuvieron el mayor impacto financiero, con una pérdida mediana de US\$1.000.000.

Además, mientras más alto fue el nivel de autoridad del responsable del fraude, las pérdidas del fraude tendieron a ser más grandes. Los propietarios/ejecutivos solo representaron el 19\% de los casos, pero ellos causaron una pérdida mediana de US\$500.000. Los administradores cometieron el 36\% de los fraudes, con una pérdida mediana de US $\$ 130.000$. En cambio, los empleados cometieron el $42 \%$ de los fraudes profesionales, pero solo causaron una pérdida mediana de US\$75.000 (ACFE, 2014).

Por otra parte, aproximadamente el $77 \%$ de los fraudes estudiados fue cometido por individuos que trabajaban en uno de los siguientes departamentos: contabilidad, operaciones, ventas, administración superior, servicio al cliente, adquisiciones y finanzas. Y al momento del estudio, solo el $14 \%$ de las organizaciones víctimas de fraude había recuperado completamente sus pérdidas.

\section{Objetivos e hipótesis}

Este estudio tiene dos objetivos: (1) analizar los efectos de una práctica extrema de earnings management, la repactación y renegociación unilateral de créditos morosos, en los estados financieros e indicadores de desempeño de la empresa La Polar; y (2) evaluar el efecto de la revelación de tales prácticas contables sobre los retornos accionarios de la firma y de sus competidoras. Con respecto al segundo objetivo se plantean dos hipótesis de estudio:

$H_{0,1}$ : La revelación de las prácticas de repactación y renegociación unilateral de créditos morosos de La Polar no generó retornos accionarios anormales negativos para sus accionistas.

$H_{0,2}:$ La revelación de las prácticas de repactación y renegociación unilateral de créditos morosos de La Polar no generó retornos accionarios anormales negativos en las firmas del sector retail.

\section{Metodología}

\section{Datos}

Se usaron datos de los estados financieros consolidados de los años 2006-2012 de la empresa La Polar S.A.; y datos de los estados financieros consolidados de las firmas de retail registradas en la SVS de Chile. También se utilizaron precios de cierre diarios de las acciones de La Polar y de las empresas de retail —Falabella, Cencosud, Ripley e Hites - transadas en la Bolsa de Comercio de Santiago, BCS, y valores de cierre diarios del Índice General de Precios de Acciones (IGPA), desde el 24 de junio de 2010 al 5 de agosto de 2011.

\section{Simulación del registro contable y evaluación de provisiones y castigos}

Se simuló el registro contable de la repactación unilateral de un crédito moroso (en el libro diario y en el libro mayor) para analizar su efecto en los reportes e indicadores de desempeño financiero de La Polar. Luego se revisaron las provisiones y castigos por incobrables reportados en los estados financieros anuales del período 2006-2012, para identificar señales o red flags que alertaran sobre posibles anomalías en los estados financieros de la firma. La revisión de las provisiones y de los saldos de las cuentas por cobrar permitió evaluar el nivel de castigo de los deudores. 


\section{Estudio de eventos}

Se aplicó la metodología de estudio de eventos, que consiste en una estimación de los retornos anormales ocurridos antes y después de un evento en particular (Brown \& Warner, 1980), evento que en esta investigación corresponde a la divulgación de un "hecho esencial". Así, se calcularon los retornos accionarios anormales de las firmas de retail que cotizaban sus acciones en la BCS, para evaluar los efectos de la divulgación del "hecho esencial" informado por La Polar a la SVS el jueves 9 de junio de 2011.

Primero, se identificó el día del evento $(t=0)$. Luego, se definió el periodo del evento como una ventana de 81 días, desde 40 días antes del evento $(t=-40)$ hasta 40 días después del evento $(t=+40)$. Esta ventana tendría información suficiente para describir lo que ocurrió con el retorno del activo ante el evento analizado. Segundo, se calculó el retorno esperado para una acción $i$ en cada día $t$ del periodo del evento $\left(\check{R}_{i t}\right)$, asumiendo condiciones normales o la ausencia del evento en estudio. Tercero, se estimó tanto el retorno anormal (residuo) de una acción $i$ para cada día $t$ del período del evento $\left(r_{i t}\right)$, como la diferencia entre el retorno observado de la acción $i$ en el día $t$ del período del evento $\left(R_{i t}\right)$ y el retorno esperado en ausencia del evento $\left(\check{R}_{i t}\right)$. Si se estudia el efecto sobre el retorno accionario de $n$ firmas, entonces se calcula el retorno anormal promedio o residuo promedio (average residual o AR) para cada día $t$ del periodo del evento, según (1).

$$
A R_{t}=\frac{\sum_{i=1}^{N} r_{i t}}{N}
$$

Cuarto, se calculó el residuo promedio acumulado en cada día $t$ (cumulative average residual o CARt) para medir el efecto promedio acumulado durante el periodo del evento.

$$
C A R_{t}=\sum_{t=-40}^{+40} A R_{t}
$$

Quinto, para medir la significancia estadística de los $r_{i t}, A R_{t}$ y $C A R_{t}$ se utilizó la prueba $t$ de Student. Se buscó evidencia que permitiera rechazar $H_{0}: r_{i t}=0 ; H_{0}: A R_{i t}=0$; y $H_{0}: C A R_{i t}=0$. El valor de $t$, con $(\mathrm{T}-1)$ grados de libertad, para los residuos viene dado por (3):

$$
t=\frac{A R_{t}}{\hat{S}(A R)}
$$

es la desviación estándar de los residuos promedios, calculada con los datos de un período sin evento. Para medir la significancia estadística del $C A R_{t}$ se utilizó (4). Se asumió que los retornos de la(s) acción(es) se distribuyen idéntica e independientemente.

$$
t=\frac{C A R_{t}}{\hat{S}(C A R)}=\frac{\sum_{t=-40}^{+40} A R_{t}}{\sum_{t=-40} \hat{S}(A R)}=\frac{\sum_{t=-40}^{+40} A R_{t}}{\sqrt{81} \times \hat{S}(A R)}
$$

Se usaron tres modelos para estimar $\check{R}_{i t}$ y detectar retornos anormales: (1) mean adjusted return, (2) market model y (3) market adjusted return. El primero, mean adjusted return, estima el retorno promedio diario de un activo durante un período sin evento. El período sin evento es anterior a la ventana de 81 días 
del período del evento. El retorno promedio se calculó usando (5), y consideró un período sin evento de $T=200$ días, desde $t=-241$ hasta $t=-41$ antes del evento.

$$
\hat{R}_{i t}=\frac{\sum_{t=-41}^{-241} R_{i t}}{T}
$$

El segundo, market model, usa el modelo de mercado (6). El modelo asume que: $E\left(\tilde{\varepsilon}_{i t}\right)=0 ; \operatorname{cov}\left(\tilde{\varepsilon}_{M t}, \tilde{\varepsilon}_{i t}\right)=0 ; y \operatorname{cov}\left(\tilde{\varepsilon}_{i t}, \tilde{\varepsilon}_{j t}\right)=0, \forall i \neq j$. El método estima una regresión lineal entre el retorno observado de un activo $\left(R_{i t}\right)$ y el retorno de un índice bursátil representativo del mercado $\left(R_{M t}\right)$, ambos correspondientes a un período sin evento.

$$
R_{i t}=\alpha_{i}+\beta_{i} \times R_{M t}+\varepsilon_{i t}
$$

Así se obtuvo una estimación de los coeficientes $\alpha_{i}$ y $\beta_{i}\left(\hat{\alpha}_{i}\right.$ y $\left.\hat{\beta}_{i}\right)$ para, a su vez, estimar los $\check{R}_{i t}$ del período del evento usando los $R_{M t}$, de acuerdo con (7):

$$
\hat{R}_{i t}=\hat{\alpha}_{i}+\hat{\beta}_{i} \times R_{M t}
$$

El tercero, market adjusted return, es similar al anterior, pero supone que el retorno estimado para el activo $i$ es igual al retorno del mercado $\check{R}_{i t}=R_{M t}$, asumiendo que $\hat{\alpha}=0$ y $\hat{\beta}=1$

\section{Resultados}

\section{Efectos de la contabilidad de repactaciones en las ratios financieras}

Se simuló la contabilización de la repactación unilateral de un crédito moroso para analizar su efecto en los indicadores financieros de la firma. Se asumió ${ }^{4}$ una venta a crédito simple a 12 meses plazo de un producto "X" por un monto de CLP $100.000^{5}$. El registro contable se muestra en la tabla 1, panel A: el asiento (1) registró una venta a crédito simple; el (2) registró el costo de la venta y rebajó las existencias; el (3) registró el ingreso financiero que se originó en el cobro de intereses por la venta a crédito ${ }^{6}$-ingreso financiero que incrementó el monto de la cuenta por cobrar-; y el (4) registró deudores incobrables por un monto equivalente al $10 \%$ de la cuenta por cobrar ${ }^{7}$, donde "deudores incobrables" es una cuenta de resultado (gasto) y "estimación incobrables" es una cuenta complementaria de la "cuenta por cobrar". La venta a crédito simple tuvo los siguientes efectos en el libro mayor: aumentó las cuentas por cobrar, aumentó los ingresos por ventas, y también los ingresos financieros; aumentó el costo de venta y también los deudores incobrables; y disminuyó las existencias. La tabla 1, panel C, muestra los saldos deudores (S.D.) y los saldos acreedores (S.A.) generados por esta transacción. 
TABLA 1

Registro contable de la venta a crédito de un producto " $\mathrm{X}$ "

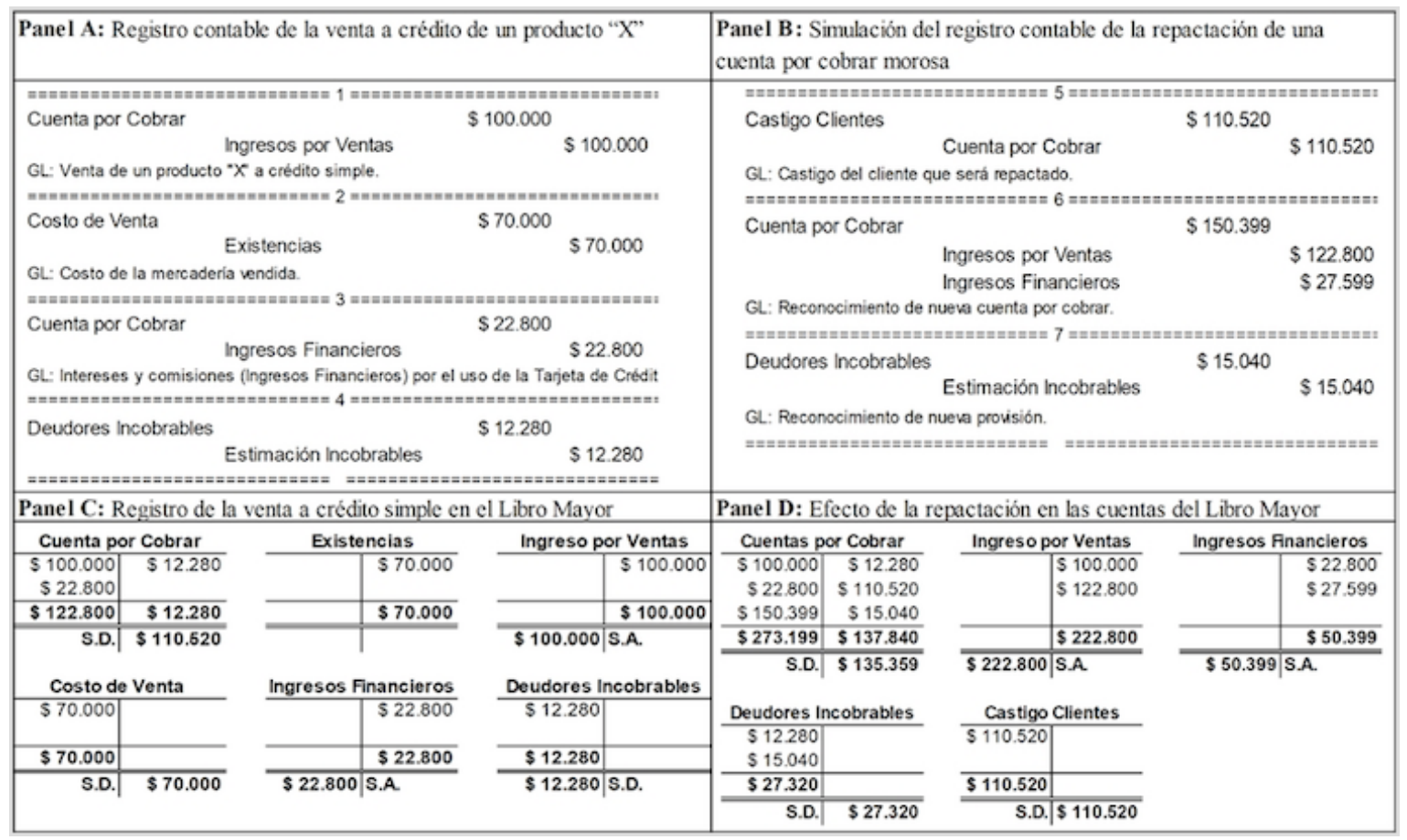

Fuente: elaboración propia

Para simular la contabilización de una repactación unilateral, se asumió que el cliente registraba una morosidad de 6 meses en el pago de la primera cuota y un saldo pendiente de CLP 122.800. También se asumió una tasa de interés máxima convencional (TMC) de 50\% anual, que fue aplicada durante los 6 meses de morosidad. La repactación otorgó contablemente un nuevo crédito al cliente, extinguió la deuda original y devengó tanto los gastos de cobranza como los intereses (calculados usando la TMC). Los asientos contables se muestran en la tabla 1, panel B. El asiento (5) registró un "castigo clientes" por un monto igual a la "cuenta por cobrar" neta de "deudores incobrables": cuentas por cobrar (CLP 100.000) + ingresos financieros (CLP 22.800) - deudores incobrables (CLP 12.280) = CLP 110.520. El asiento registró el castigo del cliente y la rebaja del saldo de la cuenta por cobrar en morosidad. Entonces, el monto castigado fue repactado por una cifra igual a la deuda pendiente (CLP 122.800), más intereses (CLP 27.599). El asiento (6) registró una nueva cuenta por cobrar por CLP 150.399 igual a la venta original, más los intereses del crédito original, más los intereses asociados a la repactación; y el (7) registró una nueva estimación de "deudores incobrables", equivalente al $10 \%$ de la cuenta por cobrar.

La repactación tuvo los siguientes efectos en los saldos de las cuentas del libro mayor (tabla 1, panel D): aumentó las cuentas por cobrar; aumentó los ingresos por ventas; aumentó los ingresos financieros; aumentó los deudores incobrables; y aumentó el castigo de clientes. Sin embargo, es posible que el asiento (5) no se haya realizado en la empresa La Polar. La duda surgió, porque este registro debió reflejarse en el Balance General y en las Notas sobre "pérdidas y castigos", pero los estados financieros de la firma no revelaron el detalle de tales "pérdidas y castigos". Además, de manera contraria a lo esperado, no se encontró evidencia de aumentos importantes del ítem "pérdidas y castigos" entre un año y otro. Por lo anterior, se presume que en la contabilidad de La Polar no se realizaba el asiento (5), sino que se registraba inmediatamente el (6), pero solo por la cuenta por cobrar y los ingresos financieros (CLP 27.599), lo cual aumentaba las cuentas por cobrar y los ingresos financieros, sin registrar un castigo de clientes. Esto estaría de acuerdo con Gerard M. Zack (2009), en cuanto a que un reporte financiero puede ser alterado mediante un plan (un sistema de repactación 
unilateral de créditos morosos) que consiga inflar activos (cuentas por cobrar), abultar ingresos y omitir notas explicativas que revelen aspectos claves de los estados financieros (pérdidas y castigos por incobrables).

Cabe señalar que el mercado objetivo de La Polar estaba compuesto por personas pertenecientes mayoritariamente a los grupos socioeconómicos C2 y C3 (medio) y D (bajo) (La Polar, 2010), lo que exponía a la firma a un riesgo de crédito significativo y a potenciales problemas de cobranza. Las cuentas por cobrar representaron el 56\% (2007), 73\% (2008), 75\% (2009) y 76\% (2010) del activo corriente de la empresa. Y la razón corriente fue de 3,81 (2007), 2,77 (2008), 2,75 (2009) y 2,25 (2010), mientras que el test ácido fue de 0,74 (2008), 0,69 (2009) y 0,55 (2010). Esto mostraba la relevancia de las cuentas por cobrar, y que un problema de incobrabilidad habría deteriorado la liquidez de la firma. Cabe recordar que una baja liquidez puede ser un incentivo para que los gerentes se involucren en la elaboración de estados financieros adulterados (Kanapickienè \& Grundienè, 2015).

Se plantearon entonces las siguientes conjeturas con respecto al sistema de repactación unilateral de créditos morosos de La Polar (2010): (1) evitaba que los clientes morosos incrementaran la cartera de cuentas por cobrar vencidas y el castigo a clientes; (2) aumentaba las cuentas por cobrar y los ingresos financieros; (3) aumentaba el activo corriente y el índice de liquidez; y (4) debido a los beneficios netos reportados, la firma incrementaba su patrimonio contable y, con ello, reducía su nivel de endeudamiento —en el año 2010, el leverage calculado sobre el patrimonio contable (bursátil) fue 2,31 (0,97)—.

La liquidez, la rentabilidad y el relativamente bajo endeudamiento mostrado por la firma facilitaron la emisión de bonos corporativos: en los años 2007 y 2010, La Polar emitió bonos corporativos por 2,4 y 2,5 veces el EBIT de esos años, respectivamente, los que obtuvieron una clasificación A, con tasas cupones entre $3,50 \%$ y $4,55 \%$ real anual. Se conjetura que los recursos provenientes de estas emisiones de bonos fueron usados para cubrir el déficit de flujo de efectivo operacional: la emisión de deuda fue equivalente a 3,2 y 2,7 veces el déficit de flujo de efectivo operacional registrado en los años 2007 y 2010, respectivamente (tabla 2, panel E). En resumen, se conjetura que la contabilidad de repactaciones unilaterales de créditos morosos permitió a La Polar mejorar la apariencia de sus estados financieros e indicadores de desempeño y ocultar su real situación financiera.

\section{Revisión de las provisiones y castigos por incobrables}

Se revisaron las provisiones y castigos por incobrables de La Polar y de las firmas del sector, durante el período 2006-2012, para identificar posibles señales de alerta (red flags). La tabla 2, panel A, muestra el comportamiento de las provisiones de La Polar, que se mantuvieron estables durante el período 2006-2010 hasta que, tras la divulgación del "hecho esencial", fueron corregidas y ajustadas de acuerdo con el nivel de morosidad que realmente había: al finalizar el primer semestre de 2011, después del ajuste al real nivel de morosidad, las provisiones representaron el $80,9 \%$ de las cuentas por cobrar (datos no tabulados); y a finales de 2011 representaron el 24,48\%. La tabla 2, panel A, también muestra las provisiones de las firmas competidoras.

La tabla 2, panel B, muestra las cuentas por cobrar como proporción de los ingresos por ventas. Las ventas disminuyeron desde CLP 445.533 millones en 2008 hasta CLP 440.876 millones en 2009 (un año de crisis financiera internacional); no obstante, las cuentas por cobrar de La Polar aumentaron desde CLP 298.633 millones en 2008 hasta CLP 417.848 millones en 2009. Así, se observó un elevado crecimiento de la ratio "cuentas por cobrar/ventas", muy por encima del nivel de la industria. Es claro que el signiæcativo incremento de las cuentas por cobrar entre los años 2008 y 2009 no estaba explicado por el crecimiento de las ventas, inconsistencia que pudo servir de señal de alerta. El valor contable de las cuentas por cobrar aumentó, pero de manera Æcticia, debido a que la repactación unilateral de créditos morosos permitió a la Ærma: (1) reconocer contablemente como activo el derecho a cobrar a un cliente moroso, en vez de reconocer una pérdida; y (2) reconocer un ingreso Ænanciero por los intereses devengados de la morosidad (lo que incrementaba el monto adeudado por el cliente moroso). 
TABLA 2

Indicadores de gestión de la cartera de clientes

\begin{tabular}{|c|c|c|c|c|c|c|c|}
\hline \multicolumn{8}{|c|}{$\begin{array}{l}\text { Evolución de las provisiones por incobrables (Panel A), de la Ratio "Cuentas por } \\
\text { cobrar/Ventas" (Panel B), del Periodo promedio de cobro (Panel C), y del Flujo por cobro de } \\
\text { ventas y créditos (Panel D). Se muestran los indicadores de La Polar durante el periodo 2006- } \\
2012 \text { (excepto en el Panel D) y de las firmas chilenas de retail constituidas como Sociedades } \\
\text { Anónimas Abiertas (Falabella, Cencosud, Ripley e Hites) durante el período 2008-2012. El } \\
\text { Panel E muestra la evolución de los ingresos de explotación, resultado operacional (EBIT), } \\
\text { beneficio neto, cuentas por cobrar netas, provisiones por incobrables, y del flujo neto originado } \\
\text { por actividades de la operación, durante el periodo 2007-2010. }\end{array}$} \\
\hline \multicolumn{8}{|c|}{ Panel A: Provisiones por Incobrables/Cuentas por cobrar (en \%) } \\
\hline Empresa & 2006 & 2007 & 2008 & 2009 & 2010 & 2011 & 2012 \\
\hline La Polar & 16,5 & 14,0 & 15,1 & 15,3 & 15,9 & 24,5 & 12,3 \\
\hline Hites & & & 0 & 11,2 & 11,2 & 11,7 & 13,7 \\
\hline Falabella & & & 6,3 & 5,5 & 4,2 & 4,1 & 4,5 \\
\hline Cencosud & & & & 9,5 & & & \\
\hline Ripley & & & 20,1 & 15,6 & 22,1 & 21,8 & 17,8 \\
\hline \multicolumn{8}{|c|}{ Panel B: Cuentas por cobrar/Ventas (en \%) } \\
\hline Empresa & 2006 & & & 2009 & 2010 & 2011 & 2012 \\
\hline La Polar & 47,7 & 56,4 & 78,9 & 111,8 & 142,4 & 105,1 & 35,4 \\
\hline Hites & & & 43 & 49,4 & & 47,3 & 41,0 \\
\hline Fala & & & 23 & 23,6 & & 24,1 & 22,0 \\
\hline Cenco & & & 9,4 & 9,9 & 12,6 & 11,7 & 11,6 \\
\hline Ripley & & & 39,0 & 31,0 & & 25 & 29,4 \\
\hline \multicolumn{8}{|c|}{ Panel C: Periodo promedio de cobro (en dias) } \\
\hline Empresa & 2006 & 2007 & 2008 & 2009 & 2010 & 2011 & 2012 \\
\hline La Pol: & 172 & 203 & 284 & 402 & 513 & 378 & 127 \\
\hline Hites & & & 155 & 179 & 172 & 170 & 148 \\
\hline Falabella & & & 85 & 85 & 85 & 87 & \\
\hline Cencosu & & & 34 & 36 & 45 & 42 & 42 \\
\hline Ripley & & & 140 & 112 & 96 & 92 & 106 \\
\hline \multicolumn{8}{|c|}{ Panel D: Flujo por cobro de ventas y créditos (en \%) } \\
\hline Empresa & 2006 & 2007 & 2008 & 2009 & 2010 & 2011 & 2012 \\
\hline La Polar & & & 54,8 & 47,5 & 39,5 & 65,2 & 90,0 \\
\hline Falabe & & & & 104,9 & 100,7 & 81,7 & 77,5 \\
\hline Cencosud & & & 106,5 & 104,0 & 101,2 & 104,4 & 105,2 \\
\hline Ripley & & & & 76,7 & 70,3 & 96,8 & 93,6 \\
\hline \multicolumn{8}{|c|}{ s de La Polar, periodo 2007-2010, en miles de pesos chilenos de cada año } \\
\hline & & 2007 & 2008 & 2009 & 2010 & & \\
\hline \multicolumn{2}{|c|}{ Ingresos de explotación } & 379.385 .949 & 445.533 .573 & 440.876 .103 & 540.190 .093 & & \\
\hline \multicolumn{2}{|l|}{ EBIT } & 56.497 .568 & 80.166 .743 & 60.881 .557 & 43.261 .659 & & \\
\hline \multicolumn{2}{|c|}{ Beneficio neto } & 33.573 .023 & 37.368 .063 & 45.776 .828 & 29.767 .140 & & \\
\hline \multicolumn{2}{|c|}{ Cuentas por cobrar } & 184.049 .992 & 298.633 .818 & 417.848 .544 & 426.439 .791 & & \\
\hline \multicolumn{2}{|c|}{$\begin{array}{l}\text { Provisión por } \\
\text { incobrables }\end{array}$} & & 53.134 .957 & 75.247 .519 & 122.605 .021 & & \\
\hline \multicolumn{2}{|c|}{ Flujo operacional } & -42.546 .990 & -68.026 .166 & .44 .467 .255 & -39.987 .860 & & \\
\hline
\end{tabular}

Fuente: elaboración propia, según Estados Financieros

La tabla 2, panel C, muestra que el período promedio de cobro (PPC) de La Polar superó los 500 días en 2010, un indicador elevado en relación con las firmas competidoras, y esto pudo constituir una segunda señal de alerta. El panel D muestra el porcentaje de pago de clientes en el estado de flujo de efectivo, el que descendió hasta 2010 y fue menor que en las firmas competidoras. Finalmente, el panel E muestra que La Polar reportó resultados operacionales (EBIT) y beneficios netos positivos, no obstante, el flujo de efectivo originado por actividades de la operación fue negativo en cada uno de los años del período 2007-2010; es decir, las medidas de ganancias devengadas fueron positivas, pero el flujo de efectivo operacional fue negativo, inconsistencia que pudo configurar una tercera señal de alerta con base en información pública. Lo anterior (panel E) podía ser explicado por el crecimiento de las cuentas por cobrar (panel B), el aumento del PPC (panel C), y por la disminución de lo recaudado en el cobro de los créditos (panel D). Estos resultados apoyarían el uso de ratiosfinancieras para detectar informes financieros adulterados.

\section{Efecto del desplome de La Polar en los retornos accionarios del sector retail}

El día del evento $(t=0)$ fue el 9 de junio de 2011 y el evento correspondió a la divulgación del "hecho esencial" informado por La Polar ese día. La tabla 3, panel A, resume los $r_{i t}$ para el día del evento y los diez días siguientes. Según los tres modelos, La Polar registró retornos negativos y significativos en los días $0,+2,+7, y+8$. Durante los días +3 al +6 no se registraron retornos, debido a que la SVS suspendió las transacciones de La Polar, dada la elevada especulación que afectaba las acciones de la compañía. Entre las fi rmas de retail, Falabella registró retornos negativos y significativos en los días $+2,+5$ y +9 (en dos modelos); Cencosud en los días +5 y +9 (dos modelos); Ripley en los días $+2,+4,+6,+7$ y +9 (dos modelos); e Hites en los días $+1,+3,+4$ (dos modelos), +5 y +7 . 
TABLA 3

Resultados del estudio de eventos, retorno anormal $\left(r_{i t}\right)$ y retorno anormal acumulado $\left(C A R_{t}\right)$

\begin{tabular}{|c|c|c|c|c|c|c|}
\hline \multicolumn{7}{|c|}{$\begin{array}{l}\text { El dia del evento }(t=0) \text { corresponde al } 9 \text { de junio de } 2011 \text {. El Panel A muestra el retorno anormal para } \\
\text { cada dia } t\left(r_{i}\right) \text {, considerando una ventana de }[0 ;+10] \text { dias a partir del evento. La Polar no registra datos } \\
\text { desde el dia }+3 \text { al }+6 \text {, debido a que la SVS ordenó suspender la transacción de sus acciones. El Panel B } \\
\text { muestra el retorno anormal acumulado a un dia } t(C A R) \text {, considerando ventanas de }[0 ;+5] \text { y }[0 ;+10] \\
\text { dias a partir del evento. En ambos paneles, los resultados corresponden a La Polar y a las empresas del } \\
\text { sector retail que cotizan sus acciones en la Bolsa de Comercio de Santiago. Entre paréntesis se muestra } \\
\text { el test- } t \text { ( }(*) \text { : Significativo al } 99 \% \text { de confianza. }(* *) \text { : Significativo al } 95 \% \text {. (***): Significativo al } 90 \% \text {. }\end{array}$} \\
\hline \multicolumn{7}{|c|}{ Panel A: Retorno anormal para cada dia $t\left(r_{t}\right)$} \\
\hline Método & $\mathrm{t}$ & La Polar & Falabella & Cencosud & Ripley & Hites \\
\hline \multirow{11}{*}{$\begin{array}{c}\text { Retorno } \\
\text { promedio } \\
\text { ajustado } \\
\text { (Mean } \\
\text { Adjusted } \\
\text { Return) }\end{array}$} & 0 & $\begin{array}{l}-42,06 \% \\
(-22,95)^{*}\end{array}$ & $\begin{array}{l}-1,12 \% \\
(-0,75)\end{array}$ & $\begin{array}{l}1,64 \% \\
(0,87)\end{array}$ & $\begin{array}{l}-0,99 \% \\
(-0,66)\end{array}$ & $\begin{array}{l}0,18 \% \\
(0,08)\end{array}$ \\
\hline & +1 & $\begin{array}{r}18,66 \% \\
(10,18)^{\circ}\end{array}$ & $\begin{array}{l}-0,93 \% \\
(-0,62)\end{array}$ & $\begin{array}{l}-0,69 \% \\
(-0,37)\end{array}$ & $\begin{array}{l}-2,31 \% \\
(-1,56)\end{array}$ & $\begin{array}{c}-5,29 \% \\
(-2,26)^{\circ}\end{array}$ \\
\hline & +2 & $\begin{array}{c}-10,77 \% \\
(-5,88)^{*}\end{array}$ & $\begin{array}{c}-3,44 \% \\
(-2,31)^{*}\end{array}$ & $\begin{array}{l}-2,29 \% \\
(-1,22)\end{array}$ & $\begin{array}{l}-4,85 \% \\
(-3,27)^{*}\end{array}$ & $\begin{array}{c}-4,08 \% \\
(-1,74)^{\cdots}\end{array}$ \\
\hline & +3 & $\cdot$ & $\begin{array}{l}-0,31 \% \\
(-0,21)\end{array}$ & $\begin{array}{l}-1,65 \% \\
(-0,88)\end{array}$ & $\begin{array}{l}-0,66 \% \\
(-0,44)\end{array}$ & $\begin{array}{c}-5,13 \% \\
(-2,19)^{*}\end{array}$ \\
\hline & +4 & - & $\begin{array}{c}-3,22 \% \\
(-2,16)^{* *}\end{array}$ & $\begin{array}{c}-3,69 \% \\
(-1,96)^{* *}\end{array}$ & $\begin{array}{c}-3,64 \% \\
(-2,45)^{* \star *}\end{array}$ & $\begin{array}{l}-6,27 \% \\
(-2,68)^{\circ}\end{array}$ \\
\hline & +5 & $\cdot$ & $\begin{array}{l}-4,64 \% \\
(-3,12)^{*}\end{array}$ & $\begin{array}{c}-3,48 \% \\
(-1,85)^{* * *}\end{array}$ & $\begin{array}{c}-2,43 \% \\
(-1,64)^{* * *}\end{array}$ & $\begin{array}{l}-8,14 \% \\
(-3,47)^{*}\end{array}$ \\
\hline & +6 & $\cdot$ & $\begin{array}{l}0,05 \% \\
(0,03)\end{array}$ & $\begin{array}{c}3,58 \% \\
(1,91)^{* * *}\end{array}$ & $\begin{array}{l}-1,03 \% \\
(-0,69)\end{array}$ & $\begin{array}{l}0,98 \% \\
(0,42)\end{array}$ \\
\hline & +7 & $\begin{array}{c}-62,63 \% \\
(-34,17)^{*}\end{array}$ & $\begin{array}{l}-1,23 \% \\
(-0,83)\end{array}$ & $\begin{array}{l}-0,05 \% \\
(-0,02)\end{array}$ & $\begin{array}{c}-3,98 \% \\
(-2,68)^{*}\end{array}$ & $\begin{array}{l}-11,19 \% \\
(-4,77)^{*}\end{array}$ \\
\hline & +8 & $\begin{array}{c}-12,37 \% \\
(-6,75)^{*}\end{array}$ & $\begin{array}{l}1,37 \% \\
(0,92)\end{array}$ & $\begin{array}{l}0,68 \% \\
(0,36)\end{array}$ & $\begin{array}{r}4,84 \% \\
(3,26)^{*}\end{array}$ & $\begin{array}{l}6,78 \% \\
(2,89)^{*}\end{array}$ \\
\hline & +9 & $\begin{array}{l}15,62 \% \\
(8,52)^{*}\end{array}$ & $\begin{array}{l}-2,09 \% \\
(-1,40)\end{array}$ & $\begin{array}{l}-2,64 \% \\
(-1,41)\end{array}$ & $\begin{array}{l}-2,18 \% \\
(-1,47)\end{array}$ & $\begin{array}{l}0,48 \% \\
(0,20)\end{array}$ \\
\hline & +10 & $\begin{array}{l}17,63 \% \\
(9,62)^{\circ}\end{array}$ & $\begin{array}{l}0,23 \% \\
(0,15)\end{array}$ & $\begin{array}{l}-1,05 \% \\
(-0,56)\end{array}$ & $\begin{array}{r}-1,31 \% \\
(-0,88)\end{array}$ & $\begin{array}{l}-2,68 \% \\
(-1,14)\end{array}$ \\
\hline \multirow{11}{*}{$\begin{array}{c}\text { Modelo de } \\
\text { mercado } \\
\text { (Market } \\
\text { Model) }\end{array}$} & 0 & $\begin{array}{r}-40,55 \% \\
(-28,06)^{\circ}\end{array}$ & $\begin{array}{l}0,58 \% \\
(0,48)\end{array}$ & $\begin{array}{c}3,39 \% \\
(2,48)^{\circ}\end{array}$ & $\begin{array}{l}0,63 \% \\
(0,50) \\
\end{array}$ & $\begin{array}{l}2,12 \% \\
(0,97)\end{array}$ \\
\hline & +1 & $\begin{array}{r}19,42 \% \\
(13,44)^{*}\end{array}$ & $\begin{array}{l}0,01 \% \\
(0,01)\end{array}$ & $\begin{array}{l}0,30 \% \\
(0,22)\end{array}$ & $\begin{array}{l}-1,46 \% \\
(-1,16)\end{array}$ & $\begin{array}{c}-4,11 \% \\
(-1,89)^{* * *}\end{array}$ \\
\hline & +2 & $\begin{array}{l}-8,61 \% \\
(-5,96)^{*}\end{array}$ & $\begin{array}{l}-1,09 \% \\
(-0,91)\end{array}$ & $\begin{array}{l}0,10 \% \\
(0,08)\end{array}$ & $\begin{array}{c}-2,59 \% \\
(-2,06)^{* *}\end{array}$ & $\begin{array}{l}-1,50 \% \\
(-0,69)\end{array}$ \\
\hline & +3 & $\cdot$ & $\begin{array}{l}0,44 \% \\
(0,37)\end{array}$ & $\begin{array}{l}-0,84 \% \\
(-0,62)\end{array}$ & $\begin{array}{l}0,01 \% \\
(0,01)\end{array}$ & $\begin{array}{c}-4,14 \% \\
(-1,91)^{* * *}\end{array}$ \\
\hline & +4 & - & $\begin{array}{l}-0,69 \% \\
(-0,58)\end{array}$ & $\begin{array}{l}-1,12 \% \\
(-0,82)\end{array}$ & $\begin{array}{l}-1,20 \% \\
(-0,96)\end{array}$ & $\begin{array}{l}-3,52 \% \\
(-1,62)\end{array}$ \\
\hline & +5 & - & $\begin{array}{c}-3,02 \% \\
(-2,52)^{\circ \bullet}\end{array}$ & $\begin{array}{l}-1,80 \% \\
(-1,32) \\
\end{array}$ & $\begin{array}{l}-0,89 \% \\
(-0,71) \\
\end{array}$ & $\begin{array}{l}-6,28 \% \\
(-2,89)^{\circ}\end{array}$ \\
\hline & +6 & $\cdot$ & $\begin{array}{c}-2,23 \% \\
(-1,86)^{*}\end{array}$ & $\begin{array}{l}1,35 \% \\
(0,99) \\
\end{array}$ & $\begin{array}{c}-3,40 \% \\
(-2,70)^{*}\end{array}$ & $\begin{array}{l}-1,07 \% \\
(-0,49) \\
\end{array}$ \\
\hline & +7 & $\begin{array}{l}-62,62 \% \\
(-43,33)^{*}\end{array}$ & $\begin{array}{l}-1,04 \% \\
(-0,86)\end{array}$ & $\begin{array}{l}0,20 \% \\
(0,15)\end{array}$ & $\begin{array}{c}-3,87 \% \\
(-3,08)^{*}\end{array}$ & $\begin{array}{l}-10,76 \% \\
(-4,95)^{*}\end{array}$ \\
\hline & +8 & $\begin{array}{r}-14,01 \% \\
(-9,70)^{*}\end{array}$ & $\begin{array}{l}-0,10 \% \\
(-0,08)\end{array}$ & $\begin{array}{l}-0,73 \% \\
(-0,54)\end{array}$ & $\begin{array}{l}3,28 \% \\
(2,61)^{*}\end{array}$ & $\begin{array}{c}5,55 \% \\
(2,55)^{* *}\end{array}$ \\
\hline & +9 & $\begin{array}{c}15,37 \% \\
(10,64)^{*}\end{array}$ & $\begin{array}{c}-2,16 \% \\
(-1,80)^{* * *}\end{array}$ & $\begin{array}{c}-2,67 \% \\
(-1,95)^{* * *}\end{array}$ & $\begin{array}{c}-2,34 \% \\
(-1,86)^{* * *}\end{array}$ & $\begin{array}{l}0,64 \% \\
(0,29) \\
\end{array}$ \\
\hline & +10 & $\begin{array}{c}18,34 \% \\
(12,69)^{*}\end{array}$ & $\begin{array}{l}1,12 \% \\
(0,94)\end{array}$ & $\begin{array}{l}-0,10 \% \\
(-0,08)\end{array}$ & $\begin{array}{l}-0,51 \% \\
(-0,40)\end{array}$ & $\begin{array}{l}-1,55 \% \\
(-0,71)\end{array}$ \\
\hline
\end{tabular}


TABLA 3 (CONTINUACIÓN)

\begin{tabular}{|c|c|c|c|c|c|c|}
\hline \multirow[b]{2}{*}{ Método } & \multirow[b]{2}{*}{$\mathrm{t}$} & \multicolumn{5}{|c|}{ Empresas del sector retail de Chile } \\
\hline & & La Polar & Falabella & Cencosud & Ripley & Hites \\
\hline \multirow{11}{*}{$\begin{array}{c}\text { Retorno de } \\
\text { mercado } \\
\text { ajustado } \\
\text { (Market } \\
\text { Adjusted } \\
\text { Return) }\end{array}$} & 0 & $\begin{array}{l}-41,22 \% \\
(-27,49)^{*}\end{array}$ & $\begin{array}{r}-0,10 \% \\
(-0,08)\end{array}$ & $\begin{array}{c}2,71 \% \\
(1,85)^{* * *}\end{array}$ & $\begin{array}{r}-0,05 \% \\
(-0,04)\end{array}$ & $\begin{array}{l}1,44 \% \\
(0,66)\end{array}$ \\
\hline & +1 & $\begin{array}{c}19,01 \% \\
(12,68)^{*}\end{array}$ & $\begin{array}{l}-0,39 \% \\
(-0,33)\end{array}$ & $\begin{array}{l}-0,10 \% \\
(-0,07)\end{array}$ & $\begin{array}{l}-1,86 \% \\
(-1,52)\end{array}$ & $\begin{array}{c}-4,52 \% \\
(-2,08)^{* *}\end{array}$ \\
\hline & +2 & $\begin{array}{l}-9,51 \% \\
(-6,35)^{4}\end{array}$ & $\begin{array}{c}-1,99 \% \\
(-1,67)^{*}\end{array}$ & $\begin{array}{l}-0,80 \% \\
(-0,54)\end{array}$ & $\begin{array}{l}-3,49 \% \\
(-2,84)^{\circ}\end{array}$ & $\begin{array}{l}-2,40 \% \\
(-1,11)\end{array}$ \\
\hline & +3 & $\cdot$ & $\begin{array}{l}0,10 \% \\
(0,09)\end{array}$ & $\begin{array}{l}-1,18 \% \\
(-0,80)\end{array}$ & $\begin{array}{l}-0,33 \% \\
(-0,27)\end{array}$ & $\begin{array}{c}-4,48 \% \\
(-2,07)^{* \bullet}\end{array}$ \\
\hline & +4 & $\cdot$ & $\begin{array}{l}-1,66 \% \\
(-1,39)\end{array}$ & $\begin{array}{l}-2,08 \% \\
(-1,42)\end{array}$ & $\begin{array}{c}-2,17 \% \\
(-1,76)^{*}\end{array}$ & $\begin{array}{c}-4,48 \% \\
(-2,07)^{* *}\end{array}$ \\
\hline & +5 & $=$ & $\begin{array}{l}-3,67 \% \\
(-3,07)^{\circ}\end{array}$ & $\begin{array}{c}-2,45 \% \\
(-1,67)^{* * *}\end{array}$ & $\begin{array}{l}-1,54 \% \\
(-1,25)\end{array}$ & $\begin{array}{c}-6,93 \% \\
(-3,19)^{*}\end{array}$ \\
\hline & +6 & - & $\begin{array}{l}-1,50 \% \\
(-1,25)\end{array}$ & $\begin{array}{l}2,09 \% \\
(1,42)\end{array}$ & $\begin{array}{c}-2,66 \% \\
(-2,16)^{* *}\end{array}$ & $\begin{array}{l}-0,33 \% \\
(-0,15)\end{array}$ \\
\hline & +7 & $\begin{array}{l}-62,76 \% \\
(-41,86)^{*}\end{array}$ & $\begin{array}{l}-1,18 \% \\
(-0,99)\end{array}$ & $\begin{array}{l}0,06 \% \\
(0,04)\end{array}$ & $\begin{array}{l}-4,01 \% \\
(-3,26)^{*}\end{array}$ & $\begin{array}{l}-10,91 \% \\
(-5,03)^{*}\end{array}$ \\
\hline & +8 & $\begin{array}{l}-13,57 \% \\
(-9,05)^{*}\end{array}$ & $\begin{array}{l}0,35 \% \\
(0,30)\end{array}$ & $\begin{array}{l}-0,29 \% \\
(-0,20)\end{array}$ & $\begin{array}{c}3,73 \% \\
(3,04)^{*}\end{array}$ & $\begin{array}{c}6,00 \% \\
(2,76)^{*}\end{array}$ \\
\hline & +9 & $\begin{array}{c}15,32 \% \\
(10,22)^{*}\end{array}$ & $\begin{array}{c}-2,20 \% \\
(-1,85)^{* * *}\end{array}$ & $\begin{array}{c}-2,71 \% \\
(-1,84)^{* * *}\end{array}$ & $\begin{array}{c}-2,39 \% \\
(-1,94)^{* * *}\end{array}$ & $\begin{array}{l}0,59 \% \\
(0,27)\end{array}$ \\
\hline & +10 & $\begin{array}{c}17,96 \% \\
(11,98)^{*}\end{array}$ & $\begin{array}{l}0,73 \% \\
(0,62)\end{array}$ & $\begin{array}{c}-0,49 \% \\
(-0,33)\end{array}$ & $\begin{array}{l}-0,89 \% \\
(-0,73)\end{array}$ & $\begin{array}{l}-1,94 \% \\
(-0,89)\end{array}$ \\
\hline \multicolumn{7}{|c|}{ Panel B: Retorno anormal acumulado a un dia $t\left(C A R_{r}\right)$} \\
\hline Método & Ventana & La Polar & Falabella & Cencosud & Ripley & Hites \\
\hline \multirow{2}{*}{$\begin{array}{c}\text { Retorno } \\
\text { promedio } \\
\text { ajustado }\end{array}$} & {$[0 ;+5]$} & $\begin{array}{l}-34,18 \% \\
(-7,61)^{*}\end{array}$ & $\begin{array}{c}-13,66 \% \\
(-3,75)^{*}\end{array}$ & $\begin{array}{l}-10,16 \% \\
(-2,21)^{* *}\end{array}$ & $\begin{array}{l}-14,87 \% \\
(-4,09)^{*}\end{array}$ & $\begin{array}{l}-28,72 \% \\
(-5,00)^{*}\end{array}$ \\
\hline & {$[0 ;+10]$} & $\begin{array}{l}-75,92 \% \\
(-12,49)^{*}\end{array}$ & $\begin{array}{l}-15,34 \% \\
(-3,11)^{*}\end{array}$ & $\begin{array}{l}-9,63 \% \\
(-1,54)\end{array}$ & $\begin{array}{l}-18,53 \% \\
(-3,76)^{*}\end{array}$ & $\begin{array}{l}-34,34 \% \\
(-4,42)^{*}\end{array}$ \\
\hline \multirow{2}{*}{$\begin{array}{l}\text { Modelo de } \\
\text { Mercado }\end{array}$} & {$[0 ;+5]$} & $\begin{array}{l}-29,74 \% \\
(-8,40)^{*}\end{array}$ & $\begin{array}{l}-3,77 \% \\
(-1,28)\end{array}$ & $\begin{array}{l}0,03 \% \\
(0,01)\end{array}$ & $\begin{array}{c}-5,51 \% \\
(-1,79)^{* * *}\end{array}$ & $\begin{array}{l}-17,44 \% \\
(-3,28)^{*}\end{array}$ \\
\hline & {$[0 ;+10]$} & $\begin{array}{l}-72,66 \% \\
(-15,16)^{*}\end{array}$ & $\begin{array}{c}-8,17 \% \\
(-2,05)^{* *}\end{array}$ & $\begin{array}{r}-1,93 \% \\
(-0,43) \\
\end{array}$ & $\begin{array}{l}-12,34 \% \\
(-2,96)^{*}\end{array}$ & $\begin{array}{l}-24,63 \% \\
(-3,42)^{*}\end{array}$ \\
\hline \multirow{2}{*}{$\begin{array}{l}\text { Retorno de } \\
\text { Mercado } \\
\text { Ajustado }\end{array}$} & {$[0 ;+5]$} & $\begin{array}{l}-31,72 \% \\
(-8,64)^{*}\end{array}$ & $\begin{array}{l}-7,70 \% \\
(-2,64)^{*}\end{array}$ & $\begin{array}{l}-3,90 \% \\
(-1,08)\end{array}$ & $\begin{array}{l}-9,44 \% \\
(-3,14)^{*}\end{array}$ & $\begin{array}{l}-21,37 \% \\
(-4,02)^{*}\end{array}$ \\
\hline & {$[0 ;+10]$} & $\begin{array}{l}-74,77 \% \\
(-15,04)^{*}\end{array}$ & $\begin{array}{l}-11,50 \% \\
(-2,91)^{*}\end{array}$ & $\begin{array}{l}-5,25 \% \\
(-1,08)\end{array}$ & $\begin{array}{l}-15,66 \% \\
(-3,84)^{*}\end{array}$ & $\begin{array}{l}-27,96 \% \\
(-3,89)^{*}\end{array}$ \\
\hline
\end{tabular}

Fuente: elaboración propia

La tabla 3, panel B, muestra el retorno anormal acumulado para un día $t\left(C A R_{t}\right)$, considerando ventanas de $5[0 ;+5]$ y $10[0 ;+10]$ días a partir del evento. La Polar registró un $C A R$ negativo y significativo a 5 días (entre $-29,74 \%$ y $-34,18 \%$ ) y a 10 días (entre $-72,66 \%$ y $75,92 \%$ ) del evento. Este retorno fue persistente y significativo en las ventanas $[0 ;+5]$ días y $[0 ;+10]$ días, de acuerdo con los tres modelos y con un 99\% de confianza. Según los resultados, la empresa más afectada fue Hites, con $C A R$ negativos y significativos a 5 días (entre - $17,44 \%$ y -28,72\%) y a 10 días (entre -24,63\% y -34,34\%) después del 9 de junio. Cabe señalar que Hites tenía un modelo de negocios similar al de La Polar. Por otra parte, la evidencia no fue concluyente con respecto al efecto en los retornos de Cencosud, cuyo $C A R$ fue negativo y significativo solo en la ventana $[0,+5]$ y de acuerdo con el primer modelo (mean adjusted return). A partir del análisis de los $r_{i t}$ y $C A R_{t}$, se concluyó que el mercado habría castigado en alguna medida el precio de las acciones de las compañías de retail, ante la posibilidad (las sospechas) de que estas también hayan realizado repactaciones unilaterales no reveladas en sus estados financieros; la empresa Hites fue la más afectada. En consecuencia, se rechazan $\mathrm{H}_{0,1}$ y $\mathrm{H}_{0,2}$.

\section{Conclusiones}

Este estudio analizó los efectos de una práctica extrema de earnings management - la repactación unilateral de créditos morosos - en los estados financieros e indicadores de desempeño de la empresa La Polar; y evaluó el efecto de la revelación de tales prácticas contables en los retornos accionarios de la firma y del sector retail de Chile. Se concluyó que la contabilidad de repactaciones unilaterales mejoró la apariencia de los estados financieros y los indicadores de desempeño de la firma; y que, una vez revelada esta situación, el mercado castigó el precio de las acciones de La Polar y también de las otras compañías de retail, ante las sospechas de 
que estas también realizaran repactaciones no reveladas en sus estados financieros, escenario en que la firma Hites fue la más afectada.

El estudio mostró que la forma de un registro contable puede ocultar el fondo económico de una operación. También mostró que un reporte financiero puede ser alterado por medio de un plan (un sistema de repactación unilateral de créditos morosos) que consiga inflar activos (cuentas por cobrar), abultar ingresos, y omitir notas explicativas que revelen aspectos claves de los estados financieros de una firma (pérdidas y castigos por incobrables). Además, el análisis de los resultados soporta la idea de que una baja liquidez (en este caso, originada en un problema de incobrabilidad) puede actuar como un incentivo para que los gerentes se involucren en la manipulación de los estados financieros. Finalmente, los resultados del estudio apoyarían el uso de ratios financieras para detectar informes financieros adulterados.

Para evitar los errores de juicio causados por este tipo de prácticas de earnings management, se requiere un correcto análisis de los estados financieros y de los fundamentos del valor económico de un negocio, junto con mayores actividades de control y monitoreo. Se espera que este estudio contribuya a una mayor comprensión y alerte sobre las prácticas de earnings management que podrían efectuarse en el sector retail de una economía emergente y en transición, en especial en los países latinoamericanos que presentan características similares a las de Chile.

\section{Referencias}

Association of Certified Fraud Examiners, ACFE (2014). Report to the Nations on Occupational Fraud and Abuse: 2014 Global Fraud Study. Austin, Texas: ACFE. Recuperado de https://www.acfe.com/rttn/docs/2014-repor t-to-nations.pdf

Badertscher, B. A., Phillips, J. D., Pincus, M. \& Rego, S. O. (2009). Earnings Management Strategies and the TradeOff between Tax Benefits and Detection Risk: To Conform or Not to Conform? The Accounting Review, 84(1), 63-97.

Becker, G. S. (1968). Crime and Punishment: An Economic Approach. Journal of Political Economy, 76(2), 169-217. Beneish, M. D. (1999). The Detection of Earnings Manipulation. Financial Analysts Journal, 55(5), 24-36.

Block, M. K. \& Gerety, V. E. (1995). Some Experimental Evidence on Differences between Student and Prisoner Reactions to Monetary Penalties and Risk. The Journal of Legal Studies, 24(1), 123-138.

Brazel, J. F., Jones, K. L. \& Zimbelman, M. F. (2009). Using Nonfinancial Measures to Assess Fraud Risk. Journal of Accounting Research, 47(5), 1135-1166.

Brown, Stephen \& Warner, Jerold B. (1980). Measuring Security Price Performance. Journal of Financial Economics, $8(3), 205-258$.

Burgstahler, D. \& Eames, M. (2006). Management of Earnings and Analysts' Forecasts to Achieve Zero and Small Positive Earnings Surprises. Journal of Business Finance \& Accounting, 33(5-6), 633-652.

Burns, N. \& Kedia, S. (2006). The Impact of Performance-based Compensation on Misreporting. Journal of Financial Economics, 79(1), 35-67.

Chih, H., Shen, C., \& Kang, F. (2008). Corporate Social Responsibility, Investor Protection, and Earnings Management: Some International Evidence. Journal of Business Ethics, 79(1/2), 179-198. Recuperado de https://www.researchgate.net/profile/Chung-Hua_Shen/publication/5149188_Corporate_Social_Respo nsibility_Investor_Protection_and_Earnings_Management_Some_International_Evidence/links/56a7441a0 8ae997e22bbcdf7.pdf

Cressey, D. (1950). The Criminal Violation of Financial Trust. American Sociological Review, 15 (6), 738-743.

Cressey, D. (1953). Other People's Money: The Social Psychology of Embezzlement. New York, New York: The Free Press.

Crutchley, C. E., Jensen, M. R. H., \& Marshall, B. B. (2007). Climate for Scandal: Corporate Environments that Contribute to Accounting Fraud. The Financial Review, 42(1), 53-73. 
Davidson, S., Stickney, C. P., \& Weil, R. L. (1987). Accounting: the Language of Business. 7th ed., Sun Lakes, Arizona: Thomas Horton and Daughters.

Dechow, P. M. \& Skinner, D. J. (2000). Earnings Management: Reconciling the Views of Accounting Academics, Practitioners, and Regulators. Accounting Horizons, 14(2), 235-250. Recuperado de https://pdfs.semanticschol ar.org/179a/a8f31458e3692be458ccdb8b8cb98faca7ec.pdf

Dorminey, J., Fleming, A. S., Kranacher, M., \& Riley, R. A. (2012). The Evolution of Fraud Theory. Issues in Accounting Education, 27(2), 555-579.

Fanning, Kurt M. \& Cogger, Kenneth O. (1998). Neural Network Detection of Management Fraud Using Published Financial Data. Intelligent Systems in Accounting, Finance \& Management, 7(1), 21-41.

Feroz, E. H., Kwon, T. M., Pastena, V. S. \& Park, K. (2000). The Efficacy of Red Flags in Predicting the SEC's Targets: an Artificial Neural Networks Approach. Intelligent Systems in Accounting, Finance \& Management, 9 (3), 145-157.

Festinger, L. (1957). A Theory of Cognitive Dissonance. Stanford, California: Stanford University Press.

Fung, M. K. (2015). Cumulative Prospect Theory and Managerial Incentives for Fraudulent Financial Reporting. Contemporary Accounting Research, 32(1), 55-75.

García-Osma, B., Gill de Albornoz, B., \& Gisbert-Clemente, A. (2005). La investigación sobre Earnings Managements. Revista Española de Financiación y Contabilidad, 34(127), 1001-1033. Recuperado de http://aeca.es/old/refc_ 1972-2013/2005/127-8.pdf

Grogger, J. (1991). Certainty vs. Severity of Punishment. Economic Inquiry, 29(2), 297-309.

Healy, P. M. \& Wahlen, J. M. (1999). A Review of the Earnings Management Literature and Its Implications for Standard Setting. Accounting Horizons, 13(4), 365-383. Recuperado de https://fisher.osu.edu/ young.53/He aly-Wahlen

Hennes, K. M., Leone, A. J., \& Miller, B. P. (2008). The Importance of Distinguishing Errors from Irregularities in Restatement Research: The Case of Restatements and CEO/CFO Turnover. The Accounting Review, 83(6), 1487-1519.

Hogan, C. E., Rezaee, Z., Riley, R. A. \& Velury, U. K. (2008). Financial Statement Fraud: Insights from the Academic Literature. Auditing: A Journal of Practice \& Theory, 27(2), 231-252.

Kanapickiené, R. \& Grundiené, Ž. (2015). The Model of Fraud Detection in Financial Statements by Means of Financial Ratios. Procedia - Social and Behavioral Sciences, 213, 321-327. Recuperado de http://ac.els-cdn.com/S1877042815059005/1-s2.0-S1877042815059005-main.pdf?_tid=abdd1aa0-126111e7-ba4e-00000aab0f01\&acdnat=1490559816_1d60c30f933a57e6235247070fba9dad

Karpoff, J. M., Lee, D. S., \& Martin, G. S. (2008). The Consequences to Managers for Financial Misrepresentation. Journal of Financial Economics, 88(2), 193-215. Recuperado de http://leeds-faculty.colorado.edu/bhagat/Con sequencesToManagersFinancialMisrepresentation.pdf

La Polar, Comunicación de un Hecho Esencial a la Superintendencia de Valores y Seguros, SVS. Santiago, 9 de junio de 2011. Recuperado de http://www.svs.gob.cl/documentos/hes/hes_2011060090353.pdf

La Polar, Memoria Anual 2010. Recuperado de http://www.nuevapolar.cl/wp-content/uploads/2014/10/pumem_2 01012_96874030_20110413_134025.pdf

Lenard, M. J. \& Alam, P. (2009). An Historical Perspective on Fraud Detection: from Bankruptcy Models to most Effective Indicators of Fraud in Recent Incidents. Journal of Forensic \& Investigative Accounting, 1(1), 1-27. Recuperado de https://www.academia.edu/1540262/An_historical_perspective_on_fraud_detection_From_ bankruptcy_models_to_most_effective_indicators_of_fraud_in_recent_incidents

National Association of Certified Fraud Examiners (1993). Cooking the Books: What Every Accountant Should Know About Fraud. Self-Study Workbook, No. 92-5401. Austin, TX: NACFE. Recuperado de http://www.acfe.com/

O'Connor, J. P.; Priem, R. L.; Coombs, J. E. \& Gilley, K. M. (2006). Do CEO Stock Options Prevent or Promote Fraudulent Financial Reporting? The Academy of Management Journal, 49 (3), 483-500. Disponible en: https://www.researchgate.net/publication/274753416_Do_CEO_Stock_Options_Prevent_or_Promote _Fraudulent_Financial_Reporting 
Persons, O. S. (1995). Using Financial Statement Data to Identify Factors Associated with Fraudulent Financing Reporting. Journal of Applied Business Research, 11 (3), 38-46. Recuperado de https://www.cluteinstitute.com /ojs/index.php/JABR/article/view/5858/5936

Ramamoorti, S. (2008). The Psychology and Sociology of Fraud: Integrating the Behavioral Sciences Component into Fraud and Forensic Accounting Curricula. Issues in Accounting Education, 23 (4), 521-533. Recuperado de http ://m.jthomasniu.org/class/781/Readings/psychoffraud.pdf

Ramamoorti, S., Morrison, D. \& Koletar, J. W. (2009). Bringing Freud to Fraud: Understanding the State-of-Mind of the C-Level Suite/White Collar Offender Through "A-B-C" Analysis. Working paper, Institute for Fraud Prevention (IFP) at West Virginia University. Recuperado de http://theifp.org/research-grants/IFP-Whitepap er-3.pdf

Ravisankar, P., Ravi, V., Raghava-Rao, G., \& Bose, I. (2011). Detection of Financial Statement Fraud and Feature Selection Using Data Mining Techniques. Decision Support Systems, 50(2), 491-500.

Schipper, K. (1989). Commentary on Earnings Management. Accounting Horizons, 3(4), 91-102.

Schmidt, P. \& Witte, A. D. (1984). An Economic Analysis of Crime and Justice: Theory, Methods and Applications. New York: Academic Press.

Song, X., Hu, Z., Du, J., \& Sheng, Z. (2014). Application of Machine Learning Methods to Risk Assessment of Financial Statement Fraud: Evidence from China. Journal of Forecasting, 33(8), 611-626.

Spathis, C., Doumpos, M., \& Zopounidis, C. (2002). Detecting Falsified Financial Statements: a Comparative Study Using Multicriteria Analysis and Multivariate Statistical Techniques. European Accounting Review, 11(3), 509-535. Recuperado de https://www.researchgate.net/publication/24080080_Detecting_falsified_financial_ statements_A_comparative_study_using_multicriteria_analysis_and_multivariate_statistical_techniques

Stice, J. D. (1991). Using Financial and Market Information to Identify Pre-Engagement Factors Associated with Lawsuits against Auditors. The Accounting Review, 66(3), 516-533.

Traslaviña, H. (2013). Llegary llevar: cómo se fraguó la estafa del siglo. 1a ed., Santiago de Chile: Mandrágora Ediciones, Colección La Plaza Mayor.

Trompeter, G. M., Carpenter, T. D., Desai, N., Jones, K. L., \& Riley, R. A. Jr. (2013). A Synthesis of Fraud-Related Research. Auditing: A Journal of Practice \& Theory, 32(1), 287-321.

Tversky, A. \& Kahneman, D. (1992). Advances in Prospect Theory: Cumulative Representation of Uncertainty.Journal of Risk and Uncertainty, 5(4), 297-323.

Ullah, S., Massoud, N., \& Scholnick, B. (2014). The Impact of Fraudulent False Information on Equity Value. Journal of Business Ethics, 120(2), 219-235. Recuperado de https://www.ualberta.ca/business/-/media/4F64C184CE B640F69CEAA9DABFFEFA50

Walker, M. (2013). How Far Can We Trust Earnings Numbers? What Research Tells Us about Earnings Management. Accounting and Business Research, 43 (4), 445-481.

Wells, J. T. (1997). Occupational Fraud and Abuse. Austin, Texas: Obsidian Publishing.

Witte, A. D. (1980). Estimating the Economic Model of Crime with Individual Data. Quarterly Journal of Economics, 94(1), 57-84.

Zack, G. M. (2009). Fair Value Accounting Fraud: New Global Risks \& Detection Techniques. 1st ed., New York, New York: John Wiley \& Sons, Inc.

\section{Notas}

1 La Tercera, viernes 10 de junio de 2011, p. 1.

2 Esta teoría le valió el premio Nobel de Economía a Daniel Kahneman en 2002. Amos Tversky había muerto en 1996.

3 Expected Utility Theory.

$4 \quad$ Las cifras contables del ejemplo obedecen a supuestos y al objetivo de lograr la comprensión del lector.

5 El ejemplo no considera los efectos tributarios de las transacciones de venta y repactaciones unilaterales.

6 Se asumen intereses y comisiones equivalentes al 22,8\% anual del monto de la venta a crédito. 
7 La cuenta por cobrar asciende a: CLP $100.000+$ CLP $22.800=$ CLP 122.800. El 10\% de ese monto es CLP 12.280.

* Artículo de investigación científica y tecnológica.

Licencia Creative Commons CC BY 4.0

Para citar este artículo: Cornejo-Saavedra, Edinson; Arias-Muñoz, Paz; Améstica-Rivas, Luis \& GuiñezCabrera, Nataly (2016). Prácticas de earning management en el sector retail de Chile. El caso La Polar. Cuadernos de Contabilidad, 17(44), 22-39. https://doi.org/10.11144/Javeriana.cc18-45.pems 